\title{
LEI DE EDUCAÇÃO AMBIENTAL EM MINAS GERAIS: BUROCRÁTICA E INCONSTITUCIONAL?
}

\author{
João Vitor Souza Teixeira ${ }^{1}$ \\ Adriel Andrade Palhares ${ }^{2}$ \\ Felipe Mol Pessoa de Carvalho ${ }^{3}$ \\ Kamila Vilela Barros Santos ${ }^{4}$ \\ Rone Frank Silva ${ }^{5}$
}

\begin{abstract}
Resumo: A Educação Ambiental é um importante instrumento de apoio para a disseminação da consciência coletiva de preservação do meio ambiente para as gerações atuais e futuras da sociedade. A Organização das Nações Unidas chama atenção aos países para a importância desta temática e os mesmos se organizam para cumprir com as premissas firmadas em acordo com a organização. No Brasil, a responsabilidade para a promoção da Educação Ambiental é atribuída à esfera pública, porém, os estados podem acionar outros atores para contribuir, como a iniciativa privada, por exemplo. O presente artigo faz um apanhado das legislações de Educação Ambiental dos estados brasileiros identificando que a legislação mineira é mais restritiva e burocrática e questiona se existe discricionariedade perante o que consta na Constituição Federal do Brasil.
\end{abstract}

Palavras-chave: Educação Ambiental; Legislação de Educação Ambiental; Deliberação Normativa (COPAM) №214/2017.

Abstract: Environmental Education is an important tool to disseminate collective consciousness of environmental preservation to current and future generations of society. The United Nations draws attention to countries as to the importance of this theme and they organize themselves in order to fulfill the organization's premises set on agreement. In Brazil, the responsibility of Environmental Education's promotion is attributed to the public sphere. However, states may call upon other actors to contribute, such as the private initiative, for example. The present paper gathers Environmental Education's laws of Brazilian states identifying if Minas Gerais' is more restrictive and bureaucratic and questions if there is discretion from what's stated in Brazilian Federal Constitution.

Keywords: Environmental Education; Environmental Education Legislation; Normative Deliberation (COPAM) №214/2017.

\footnotetext{
${ }^{1}$ Federação das Indústrias do Estado de Minas Gerais. E-mail: jvst2013@gmail.com

2 Federação das Indústrias do Estado de Minas Gerais. E-mail: apalhares@fiemg.com.br

3 Federação das Indústrias do Estado de Minas Gerais. E-mail: fmpessoa@fiemg.com.br

${ }^{4}$ Federação das Indústrias do Estado de Minas Gerais. E-mail: kvilela@fiemg.com.br

${ }^{5}$ Federação das Indústrias do Estado de Minas Gerais. E-mail: rone.silva@fiemg.com.br
} 


\section{Introdução}

A Educação Ambiental surge como importante ferramenta para garantir a conservação e preservação do meio ambiente, para as gerações atuais e, principalmente para as futuras. É papel de todos compreender os impactos das suas atividades no meio ambiente e entender como podem contribuir para redução e mitigação destes impactos, o que pode ser viabilizado pela consciência ambiental coletiva. Segundo a Organização das Nações Unidas para a Educação, a Ciência e a Cultura - UNESCO, Educação Ambiental é definida como um processo que busca tornar a comunidade consciente e integrada com o meio ambiente, fornecendo-lhe conhecimento, capacidade e estímulo, tornando-a parte integrante do meio, com capacidade de agir de forma individual e coletiva, no intuito de alcançar as maneiras de solucionar os problemas ambientais atuais e futuros (UNESCO, 1987).

Concordante, Jacobi (2002, p.10), diz que "a Educação Ambiental deve ser vista como um processo de permanente aprendizagem que valoriza as diversas formas de conhecimento e forma cidadãos com consciência local e planetária".

Esse esforço vem sendo disseminado mundialmente, com principal apoio da Organização das Nações Unidas de forma a conscientizar os países a adotarem suas próprias políticas de Educação Ambiental. Isto fica evidenciado, entre outras iniciativas da organização, na Conferência de 1972 sobre o Desenvolvimento e Meio Ambiente Humano, realizada em Estocolmo com a participação de 113 países. Na ocasião, foram estabelecidos 26 princípios para o Desenvolvimento Sustentável, sendo o princípio 19 pautado no tema de Educação Ambiental, dizendo: "É indispensável um esforço para a educação em questões ambientais, dirigida tanto às gerações jovens como aos adultos e que preste a devida atenção ao setor da população menos privilegiado" (ONU, 1971 , s.p.).

Como protagonista da disseminação da Educação Ambiental, cada país, então, estabelece diretrizes e caminhos para sua promoção, sendo eles norteadores das demais esferas integrantes da comunidade, para que possam espelhar suas ações e, em conjunto, promover o tema como um todo.

No Brasil, existe uma diretriz federal sobre a educação, pautada na Constituição Federal de 1988, atribuindo ao poder público a responsabilidade de promovê-la. Os estados, por sua vez, podem ser mais restritivos no tema, atribuindo novas responsabilidades às demais esferas, como iniciativa privada, escolas etc. O importante é que os estados não sejam inconstitucionais ou desviem a responsabilidade já elencada ao ator público.

Neste sentido, faz-se necessário o presente artigo para elucidar como o estado de Minas Gerais tem se comportado na problemática supracitada, uma vez que é o único que possui uma legislação específica para a Educação Ambiental promovida pela iniciativa privada. O objetivo do mesmo é comparar a Deliberação Normativa 214/2017 que versa sobre este tema com as legislações dos demais estados, a fim de compreender as principais diferenças 
na atuação da Educação Ambiental destes estados.

Para tanto, a seguir serão analisadas a Constituição Federal Brasileira e a Estadual de Minas Gerais, bem como sua deliberação estadual para posteriormente compará-la com as dos demais estados do país.

\section{Promoção da Educação Ambiental nas Constituições}

\section{Constituição Federal}

A Constituição Federal Brasileira dispõe que 0 meio ambiente ecologicamente equilibrado é direito de todos e que é dever do poder público e da coletividade defendê-lo e preservá-lo para gerações presentes e futuras (BRASIL, 1988). Ela ainda versa sobre a importância da Educação Ambiental na garantia do disposto no art. 225. Nesse mesmo artigo, em seu inciso VI, nota-se a determinação ao Poder Público de "promover a Educação Ambiental em todos os níveis de ensino e a conscientização pública para a preservação do meio ambiente".

No Brasil, a Lei Federal n 9.795, de 27 de abril de 1999 é regulamentada pelo Decreto Federal no 4.281, de 25 de junho de 2002, e institui a Política Nacional de Educação Ambiental, a qual se firma como parte imprescindível para a educação no país, devendo ser aplicada em caráter formal e não formal, em todo o processo educativo.

Há de se ressaltar, porém, que os debates técnico-jurídicos que envolvam a seara ambiental - este incluído - devem ser balizados também por outros pressupostos da sustentabilidade contidos na Carta Magna, além daquele contido no art. 225: ordem econômica, função social da propriedade, direito ao pleno emprego, livre iniciativa, erradicação da pobreza, ordenação territorial urbana, política agrícola e o desenvolvimento nacional. Sublinha-se ainda que a sustentabilidade é composta pelos pilares do desenvolvimento econômico, desenvolvimento social e proteção ambiental (Brundtland, 1987).

\section{Constituição Estadual de Minas Gerais}

Com o objetivo de regulamentar o inciso I do $\$ 1^{\circ}$ do art. 214 da Constituição do Estado de Minas Gerais, a Lei Estadual no 15.441/2005 dispõe que a Educação Ambiental será desenvolvida em todos os níveis e modalidades no processo educativo, em caráter formal e não formal. Ademais, a Lei apresenta diretrizes da Educação Ambiental para o sistema estadual de ensino, com práticas educativas interdisciplinares, contínuas e permanentes. Contudo, cabe à Secretaria de Estado de Meio Ambiente e Desenvolvimento Sustentável (SEMAD) identificar temas prioritários de Educação Ambiental sujeitos à apreciação da Secretaria de Estado de Educação no desenvolvimento de temas nas unidades estaduais de ensino.

No Estado de Minas Gerais, as diretrizes de Educação Ambiental foram 
trazidas pelo Decreto Estadual no 44.264, de 24 de março de 2006, que institui a Comissão Interinstitucional de Educação Ambiental do Estado de Minas Gerais (CIEA/MG), a qual tem como objetivo "promover a discussão, a gestão, a coordenação, o acompanhamento e avaliação dos programas, projetos $\mathrm{e}$ ações e de implementar as atividades de Educação Ambiental no estado de Minas Gerais, observadas as disposições legais." (MINAS GERAIS, 2006). Cabe destacar que o Decreto, então, considera a promoção da Educação Ambiental como dever do Estado.

\section{Deliberação Normativa COPAM n²14/2017}

Em 26 de abril de 2017, a DN CPAM no 214, alterada pela DN COPAM $n^{\circ}$ 238/2020, estabeleceu diretrizes para a elaboração e execução dos Programas de Educação Ambiental (PEA) no âmbito dos processos de licenciamento ambiental dos empreendimentos mineiros, transferindo parte da responsabilidade da promoção da Educação Ambiental para as entidades privadas.

Em razão disso, cria-se uma dicotomia acerca do compartilhamento da responsabilidade de executar a Educação Ambiental nos estados. Para entender melhor como essas unidades federativas dispõem sobre tal matéria, realizou-se um comparativo entre as normas de Educação Ambiental em todos os estados brasileiros e a DN COPAM no 214/2017 de Minas Gerais. Considerando ser Minas Gerais um dos estados que mais se aprofundou em relação às legislações sobre 0 assunto, priorizaram-se as alterações significativas ocorridas nas suas normas desde 2017.

Desde a publicação da DN COPAM no 214/2017, os empreendimentos passíveis de licenciamento ambiental em Minas Gerais passaram a ser enquadrados para elaboração e execução do PEA. Para melhor compreender quais seriam esses empreendimentos causadores de impacto ambiental, podese citar Sánchez, que diz que a locução impacto ambiental é, na maioria das vezes, associada a algum dano indesejado na natureza (SANCHEZ, 2013).O autor ainda destaca a existência de múltiplas definições de impacto ambiental na literatura técnica, sendo uma delas "qualquer alteração no meio ambiente em um ou mais de seus componentes - provocada por uma ação humana". (SÁNCHEZ, 2013 apud Moreira, 1992, p.113).

Ainda de acordo com Sánchez (apud Munn, 1975, p. 23.), a avalição de impacto ambiental pode ser entendida como "atividade que visa identificar, prever, interpretar e comunicar informações sobre as consequências de uma determinada ação sobre a saúde e o bem-estar humanos". A respeito da necessidade de elaboração de um PEA de acordo com os impactos ambientais, a DN COPAM $n^{\circ} 217 / 17$ versa: 
$\S 2^{\circ}-$ Em virtude das características, localização, impactos e grupos sociais da Área de Abrangência da Educação Ambiental - Abea - do empreendimento ou atividade, o órgão ambiental poderá determinar a elaboração e execução do PEA nos casos necessários, devidamente motivado, como informação complementar, independentemente do tipo dos estudos apresentados. (MINAS GERAIS, 2017).

Para elaboração do PEA, a DN no 214/2017, traz como instrumento o Diagnóstico Socioambiental Participativo (DSP), que deverá se basear em mais de uma técnica participativa, com vistas ao envolvimento dos diferentes grupos sociais, definidos no inciso IV do art. $2^{\circ}$ da DN nº 214/2017:

IV - Diagnóstico Socioambiental Participativo - DSP: instrumento de articulação e empoderamento que visa diagnosticar, sensibilizar, mobilizar, compartilhar responsabilidades e motivar os grupos sociais impactados pelo empreendimento, a fim de se construir uma visão coletiva da realidade local, identificar as potencialidades, os problemas locais e as recomendações para sua melhoria, considerando os impactos socioambientais do empreendimento, resultando em uma base de dados que norteará e subsidiará a construção e implementação do PEA.

Outro aspecto a se destacar com relação à DN COPAM no 214/2017 é a necessidade de delimitação da Área de Abrangência da Educação Ambiental (Abea), tanto para elaboração e execução do PEA quanto para solicitação de sua dispensa. A DN traz em seu inciso VI do art. $2^{\circ}$ a definição de Abea como:

VI - Área de Abrangência da Educação Ambiental - Abea: Área contida na Área de Influência Direta - AID - do meio socioeconômico, se limitando a esta, sujeita aos impactos ambientais diretos e negativos decorrentes da implantação e operação da atividade ou empreendimento, considerando os grupos sociais efetivamente impactados. 
Além das alterações significativas já mencionadas no presente estudo, destaca-se a distinção entre os públicos-alvo do PEA, sendo eles: 1) Público Interno, direcionado aos trabalhadores próprios e de empresas contratadas, e 2) Público Externo, direcionado às comunidades localizadas na Abea da atividade ou empreendimento. Não obstante, destaca-se também a abrangência de aplicação das ações do PEA, que deverá ser definida de acordo com os limites da Abea da atividade ou empreendimento, podendo contemplar os meios biótico, físico e socioeconômico, conforme resultados obtidos no DSP. Ainda, de acordo com a norma, para a definição de Abea consideram-se os impactos diretos e negativos (MINAS GERAIS, 2017).

A DN COPAM $n^{\circ}$ 214/2017 também enfatiza a realização do Projeto Executivo do PEA, a critério do empreendedor, antes da aprovação pelo órgão ambiental licenciador, sem prejuízo de eventuais adequações ou correções necessárias que possam ser solicitadas posteriormente pelo mesmo órgão.

Além disto, ressalta-se que 0 art. 11 aventa a possibilidade de parceria com outros empreendedores e com instituições públicas e privadas para o público externo além de buscar sinergia com ações públicas já desenvolvidas na região, desde que as ações tenham correlação com os impactos do empreendimento (MINAS GERAIS, 2017).

Faz-se necessário então um estudo sobre como esta norma se aplica na prática, além de como ela reflete perante as legislações dos demais estados brasileiros, a fim de encontrar sinergia e similaridade entre eles e apontar suas diferenças.

Por meio de uma análise criteriosa da DN COPAM n 214/2017 e das legislações de Educação Ambiental dos outros estados brasileiros, é possível levantar o questionamento da existência de discricionariedade dos processos, bem como uma lacuna na atuação e priorização do poder público com a Educação Ambiental.

\section{Metodologia}

A primeira etapa para elaboração do estudo foi uma análise técnica e jurídica da Deliberação Normativa 214/2017 de Minas Gerais por um time de cinco especialistas da área, sendo quatro engenheiros ambientais e um advogado ambiental. Essa análise trouxe a possibilidade de definir 8 critérios importantes para a compreensão da norma e sua execução. Os critérios definidos foram: 1) obrigatoriedade de realização do PEA; 2) critérios para dispensa do PEA; 3) público-alvo; 4) metodologia e responsabilidade de execução; 5) procedimentos de revisão; 6) atualização e acompanhamento do plano; 7) nível de diversidade dos públicos envolvidos e 8) possibilidade de parcerias entre iniciativa pública e privada.

Em seguida, foi realizada uma pesquisa pelos mesmos especialistas nos sites oficiais dos demais estados brasileiros sendo eles: Assembleia Legislativa e Diário Oficial. Essa pesquisa levantou a legislação de Educação Ambiental de 
cada estado e do Governo Federal.

O Quadro 1 identifica os estados brasileiros que possuem legislação referente à Educação Ambiental e aqueles que não possuem, bem como suas referidas legislações.

Quadro 1: Legislação de Educação Ambiental no Brasil.

\begin{tabular}{|c|c|c|c|}
\hline Lei Federal & $\begin{array}{l}\text { Lei Federal } \mathrm{n}^{\circ} \\
9.795 / 1999\end{array}$ & $\begin{array}{l}\text { Decreto Federal no } \\
4.281 \text {, de } 25 \text { de junho } \\
\text { de } 2002\end{array}$ & - \\
\hline ESTADO & NORMA & REGULAMENTAÇÃO & $\begin{array}{l}\text { DELIBERAÇÃO } \\
\text { NORMATIVA }\end{array}$ \\
\hline Minas Gerais & Lei no 15.441/2005 & $\begin{array}{l}\text { Decreto Estadual } \\
\mathrm{n} 044.264 / 2006\end{array}$ & $\begin{array}{c}\text { DN no } 214 / 2017 \text { e } \\
\text { DN no } 238 / 2020\end{array}$ \\
\hline Acre & - & - & - \\
\hline Alagoas & Lei nº 7.804/2016 & - & - \\
\hline Amapá & Lei $n^{0} 1.295 / 2009$ & - & - \\
\hline Amazonas & Lei nº 3.222/2008 & - & - \\
\hline Bahia & Lei no $12.056 / 2011$ & - & - \\
\hline Ceará & Lei no 14.892/2011 & Decreto $n^{\circ} 31.405 / 2014$ & - \\
\hline Distrito Federal & $\begin{array}{c}\text { Lei Distrital } \\
\mathrm{n}=3.833 / 2006\end{array}$ & Decreto n $31.129 / 2009$ & - \\
\hline Espírito Santo & Lei no 9265/2009 & - & - \\
\hline Goiás & Lei no $16.586 / 2009$ & Decreto no $7.821 / 2013$ & - \\
\hline Maranhão & Lei no 9.279/2010 & Decreto n $28.549 / 2012$ & - \\
\hline Mato Grosso & Lei no 10.903/2019 & $\begin{array}{c}\text { Resolução Normativa } \\
\text { no 002/2015 }\end{array}$ & - \\
\hline $\begin{array}{c}\text { Mato Grosso do } \\
\text { Sul }\end{array}$ & Lei $n^{\circ} 5.287 / 2018$ & - & - \\
\hline Pará & - & - & - \\
\hline Paraíba & Lei no $7.718 / 2005$ & Decreto $\mathrm{n}^{\circ} 36.156 / 2015$ & - \\
\hline Paraná & Lei no $17.505 / 2013$ & - & - \\
\hline Pernambuco & Lei no $16.688 / 2019$ & - & - \\
\hline Piauí & Lei $n^{\circ}$ 6.565/2014 & - & - \\
\hline Rio de Janeiro & Lei nº 3.325/1999 & - & - \\
\hline $\begin{array}{l}\text { Rio Grande do } \\
\text { Norte }\end{array}$ & Lei no 272/2004 & - & - \\
\hline Rio Grande do Sul & Lei no $13.597 / 2010$ & - & - \\
\hline Rondônia & - & - & - \\
\hline Roraima & Lei no 445/2004 & - & - \\
\hline Santa Catarina & Lei no 13.558/2005 & Decreto no 3.726/2010 & - \\
\hline São Paulo & Lei no 12.780/2007 & Decreto n $63.456 / 2018$ & - \\
\hline Sergipe & Lei no 6.882/2010 & - & - \\
\hline Tocantins & Lei $\mathrm{n}^{0}$ 1.374/2003 & - & - \\
\hline
\end{tabular}

Fonte: Elaborado pelos autores (2021).

Os critérios definidos foram comparados com as legislações dos demais estados, a fim de identificar aqueles que se apresentam mais ou menos restritivos e/ou burocráticos para a iniciativa privada, no que se refere à sua responsabilidade frente à disseminação da Educação Ambiental.

Revbea, São Paulo, V. 16, № 6: 378-396, 2021. 
Mediante o universo legislativo apresentado, cada legislação foi lida e interpretada, a fim de apontar as principais diferenças em cada um dos critérios selecionados e identificar os graus de restrição apresentados por cada estado. O resultado dessa análise será discutido a seguir.

\section{Discussão}

\section{Análise Técnica}

Conforme elucidado pelo Quadro 1, com exceção do Acre, Pará e Rondônia, os estados brasileiros apresentam uma lei referente à Educação Ambiental. A regulamentação dessa lei, porém, é feita pelos decretos estaduais, que traçam diretrizes para execução dos Planos de Educação Ambiental. Apenas oito estados, além do Distrito Federal, já desenvolveram um decreto nesse sentido, sendo eles: Ceará, Goiás, Maranhão, Mato Grosso, Minas Gerais, Paraíba, Santa Catarina e São Paulo. Minas Gerais se destaca como o único estado a possuir Deliberação Normativa que se aprofunda ainda mais nas diretrizes sobre 0 plano, voltadas especificamente para empreendimentos sujeitos ao processo de licenciamento ambiental (Figura 1).

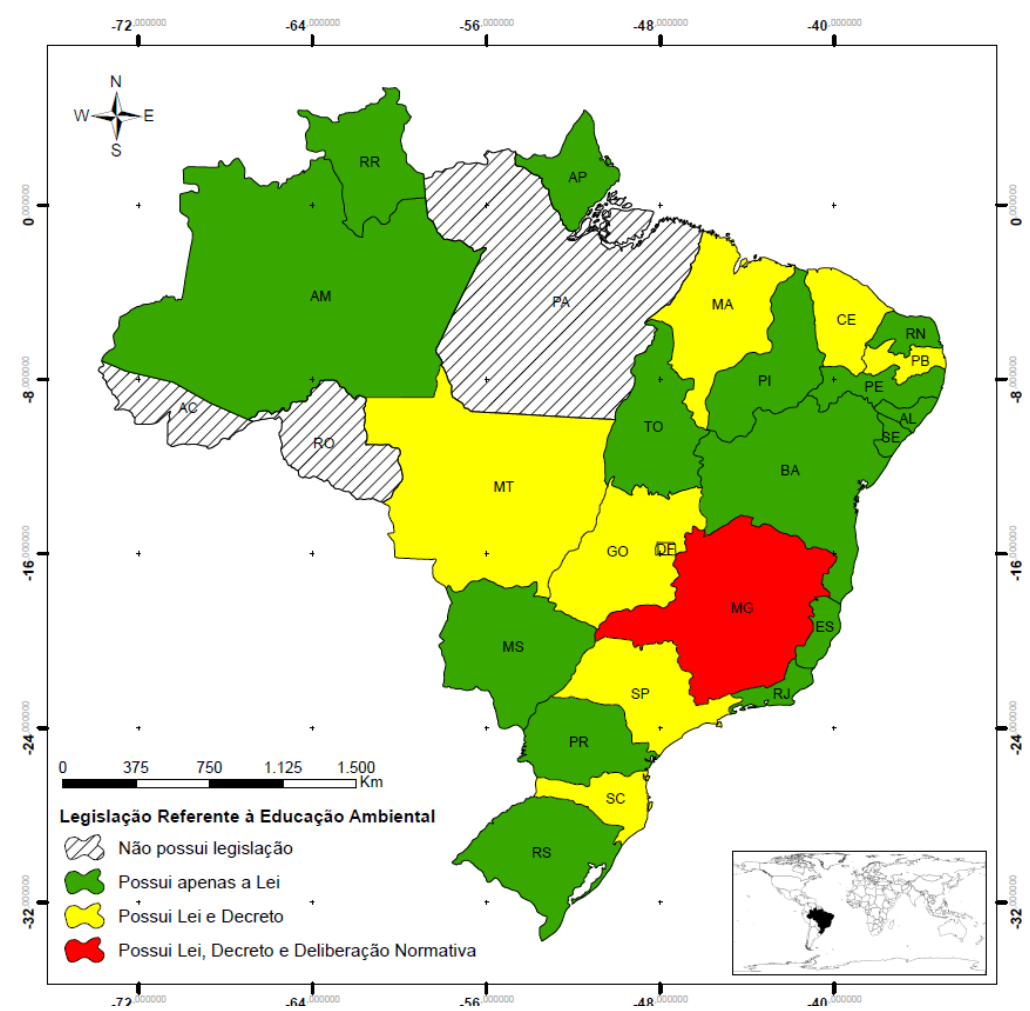

Figura 1: Estados que possuem legislação correlata ao tema de Educação Ambiental

Fonte: Elaborado pelos autores (2021).

Atualmente, tem-se o conhecimento de que o estado do Rio de Janeiro também se encontra em processo de desenvolvimento de uma DN similar, 
porém sem data certa de publicação. Quanto aos demais estados, não foram obtidas informações a respeito do desenvolvimento de uma DN de Educação Ambiental específica para os processos de licenciamento ambiental da iniciativa privada.

Dessa forma, a comparação entre a DN de Minas Gerais e os decretos dos demais estados provar-se-á de grande divergência, servindo para conclusão do presente artigo no sentido da maturidade legislativa dos estados brasileiros.

No que tange à obrigatoriedade de elaboração do Plano de Educação Ambiental, com exceção do Estado de Minas Gerais, todos os demais apontam para o órgão público como protagonista da elaboração e execução do plano. No Distrito Federal, assim como nos estados da Paraíba e Santa Catarina, é instituída a Comissão Interinstitucional de Educação Ambiental (CIEA), que fica responsável por acompanhar, avaliar e implementar as ações do plano (vide Figura 2). Os demais estados também preveem a constituição de órgãos gestores para a mesma finalidade. O Distrito Federal atribuiu à Secretaria Executiva a competência de propor as diretrizes para o plano, enquanto os demais deixaram essa atribuição para as suas respectivas Secretarias de Meio Ambiente e/ou Desenvolvimento Sustentável e de Educação. São Paulo foi o único estado que não especificou essa obrigatoriedade.

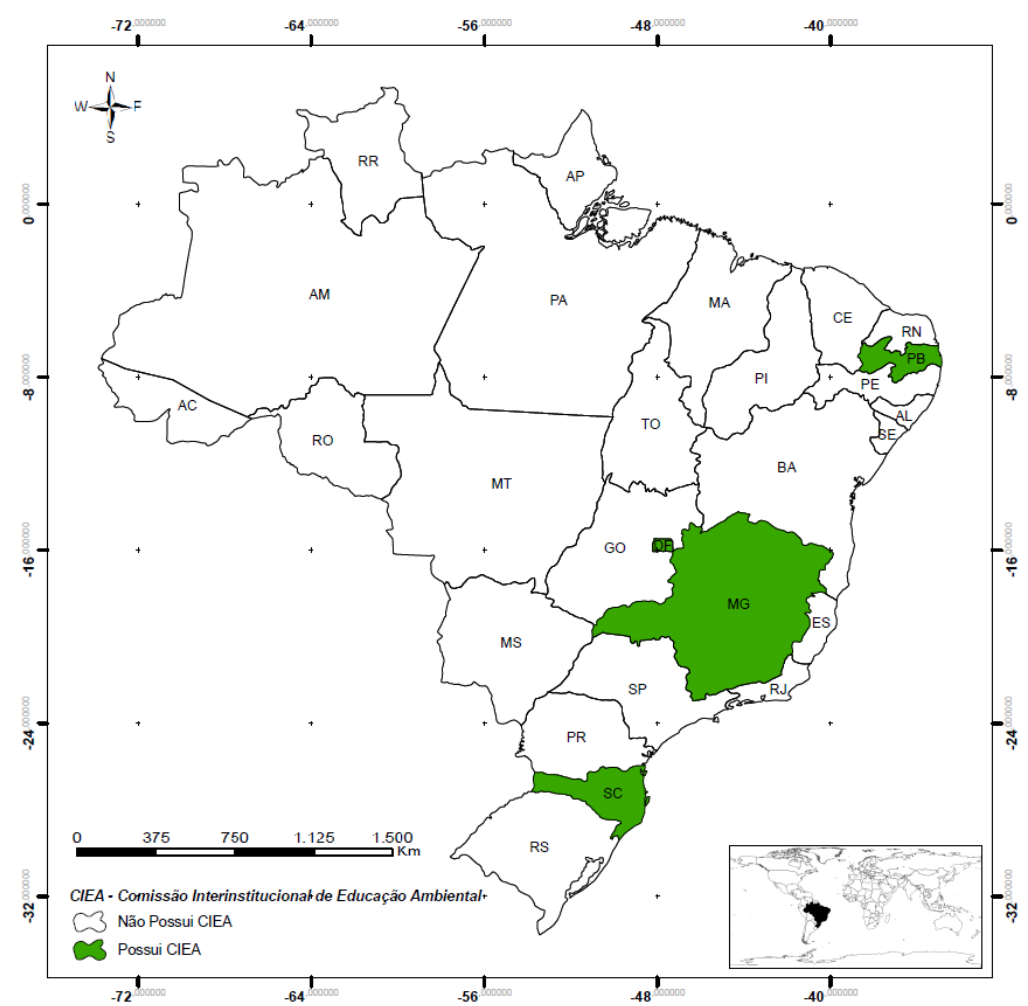

Figura 2: Estados que possuem CIEA.

Fonte: Elaborado pelos autores (2021). 
Cabe ressaltar que, além de Minas Gerais, Maranhão foi o único a atribuir parte da responsabilidade do plano para a iniciativa privada, por meio dos processos licenciatórios. Em ambos os Estados, fica a critério da Secretaria de Meio Ambiente determinar, em cada processo, qual deles deverá apresentar PEA. Em Minas Gerais, é citado ainda o Diagnóstico Socioambiental Participativo (DSP) como instrumento fundamental para essa determinação. $O$ único Estado a fazer menção do processo de dispensa do PEA é Minas Gerais, traçando diretrizes para a formalização de uma solicitação de dispensa por parte dos empreendedores que julgarem ter argumentos técnicos para tal.

O público-alvo do Plano de Educação Ambiental é um item primordial da legislação. Na DN de Minas Gerais, ele é determinado por meio da criação da Área de Abrangência da Educação Ambiental (Abea), que seria a região de impactos diretos e negativos provenientes das atividades licenciadas no órgão. A legislação mineira é a única que limita o raio de abrangência da Educação Ambiental, enquanto as demais versam sobre o Estado como um todo, sendo a educação formal e informal o denominador comum, estando presente em todos os decretos. Santa Catarina, Ceará e Maranhão englobam os agentes de ensino também como público-alvo da Educação Ambiental, agindo como multiplicadores. O Maranhão ainda cita especificamente as comunidades indígenas, quilombolas e campestres como público-alvo mandatório dentro do plano. Com exceção do Mato Grosso, todas as legislações citam a parceria público-privada e a que se dá com demais órgãos da sociedade. Elas funcionam não só para a elaboração e execução do plano, mas também como público-alvo.

A metodologia de execução dos planos surge em vários níveis de especificidade em cada legislação. Os decretos do Distrito Federal e dos Estados da Paraíba, Goiás, Ceará e São Paulo não apresentam uma metodologia clara, ao passo que Maranhão e Santa Catarina apresentam diretrizes gerais. Mato Grosso se destaca determinando que, para cada modalidade de público-alvo, haverá uma metodologia específica. E, Minas Gerais, por sua vez, traz à tona novamente o DSP como ferramenta para determinação de metodologia de elaboração e execução do plano.

Para a execução do plano, as legislações incentivam a parceria entre os órgãos estaduais e iniciativas privadas. O Estado do Mato Grosso foi o único a não citar parcerias, por entender que a responsabilidade é inteiramente do poder público. A grande diferença nesse ponto fica na forma como a parceria é firmada. Em Minas Gerais, a iniciativa privada é responsável pela elaboração e execução do PEA, além de ter a competência de buscar, em outras entidades, apoio para a sua execução. Enquanto isso, no restante do país, a tratativa se mostra contrária, ou seja, os órgãos públicos ficam responsáveis por buscar essas parcerias (vide Figura 3). 


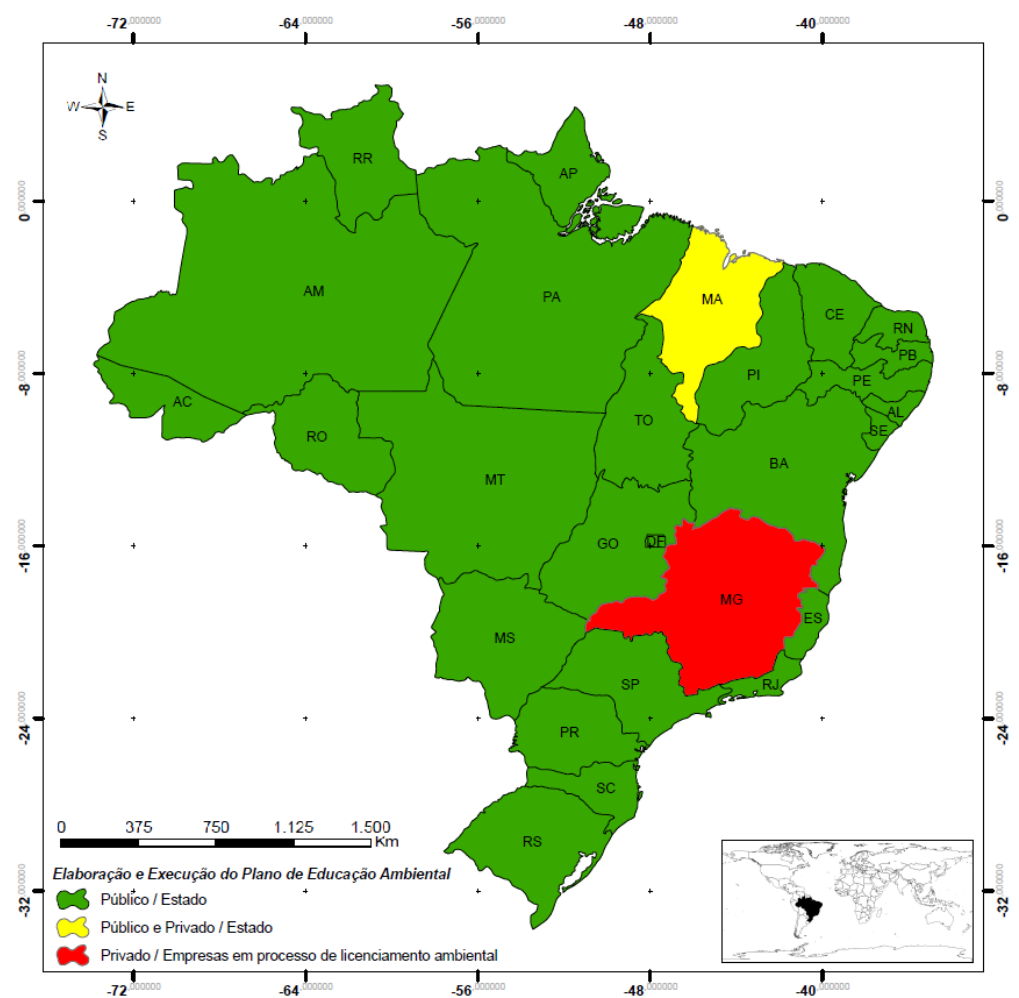

Figura 3 - Características das parcerias público-privadas de cada estado

Fonte: Elaborado pelos autores (2021).

Sobre as revisões, complementações e atualizações do plano, Minas Gerais agrega ao empreendedor que desenvolver o plano, a obrigatoriedade de comunicar ao órgão ambiental licenciador as alterações ocorridas, a serem apresentadas nos casos previstos nos $\S \S 3^{\circ}$ e $6^{\circ}$ do art. $6^{\circ}$ e no art. 15 da DN $n^{\circ} 214$. Dentre os outros Estados analisados, os únicos que preveem diretrizes para revisão do plano são Goiás e São Paulo, porém atribuindo essa responsabilidade aos próprios órgãos públicos que o elaboraram.

Para viabilizar o acompanhamento dos planos, Minas Gerais apresenta mais uma peculiaridade em sua Deliberação Normativa. $O$ empreendedor será responsável por enviar um formulário de acompanhamento anualmente ao órgão ambiental, até trinta dias após o final do primeiro semestre de cada ano, e o relatório de acompanhamento, a ser apresentado anualmente, até trinta dias após o final do segundo semestre de cada ano de execução do PEA. Essa obrigação não é apresentada em nenhum outro estado brasileiro. Goiás cita em sua legislação a criação de indicadores quantitativos e qualitativos de acompanhamento, que serão levantados no decorrer dos projetos executivos pelo próprio órgão gestor.

Outra particularidade da legislação mineira é a possibilidade de o empreendedor executar o PEA antes de ser aprovado pelo órgão, sendo prevista ainda a não aprovação por parte do órgão em tempo hábil. Nesse caso, adequações ou correções solicitadas posteriormente pelo órgão 
ambiental licenciador serão executadas pelo empreendedor sem qualquer prejuízo em sua realização.

Após analisar as legislações pertinentes aos Planos de Educação Ambiental no território brasileiro, foi possível realizar inferências e considerações, as quais ainda serão abordadas neste artigo.

\section{Análise Jurídica}

O art. 3ㅜ, inciso V, da Lei Federal no 9.795/1999 é claro ao dispor que as empresas têm que promover programas para capacitação dos trabalhadores e melhoria no ambiente de trabalho. Tal lei determina que as empresas devem promover a Educação Ambiental somente de seus trabalhadores, e não da comunidade vizinha.

Dispõe o inciso II do art. 50 da Constituição Federal (CF) que "ninguém será obrigado a fazer ou deixar de fazer alguma coisa senão em virtude de lei". Logo, a julgar pelo disposto na Lei Federal de Educação Ambiental, não há que se falar em obrigação das empresas de promoverem a Educação Ambiental nas comunidades vizinhas, visto que isso não está disposto na referida norma.

O inciso I, $\S 1^{\circ}$, do artigo 214 da Constituição Estadual é ainda mais relapso do que a Constituição Federal, visto que nem mesmo institui obrigações às empresas no que tange à Educação Ambiental. A saber:

$\S 1^{\circ}$ - Para assegurar a efetividade do direito a que se refere este artigo, incumbe ao Estado, entre outras atribuições:

I - promover a Educação Ambiental em todos os níveis de ensino e disseminar, na forma da lei, as informações necessárias à conscientização pública para a preservação do meio ambiente; (MINAS GERAIS, 2020). (grifo nosso).

A Lei Estadual no 15.441/2005, que regulamenta justamente o inciso acima colacionado, também é silente quanto à instituição de obrigações ambientais às empresas. Essa norma estadual, inclusive, aborda o tema de Educação Ambiental única e exclusivamente voltado para todos os "níveis e modalidades do processo educativo".

Já a DN no 214/2017, que estabelece as diretrizes para a elaboração e a execução dos Programas de Educação Ambiental no âmbito dos processos de licenciamento ambiental no Estado de Minas Gerais, foi estabelecida com base no inciso IX, $§ 1^{\circ}$, art. 214, da Constituição Estadual. Tal inciso dispõe que é possível "estabelecer, através de órgão colegiado, com participação da sociedade civil, normas regulamentares e técnicas, padrões e demais medidas de caráter operacional, para proteção do meio ambiente e controle da utilização racional dos recursos ambientais". Isso, por si só, demonstra que a DN não 
encontrou amparo legal em nenhuma das normas anteriormente aqui citadas.

Destaca-se o fato de que o Licenciamento Ambiental Estadual sequer se aplica às instituições de ensino de Minas Gerais, mas sim às empresas que sejam consideradas causadoras de significativo impacto ambiental. Isso, de imediato, já afasta as obrigações trazidas pela DN no 214/2017 daquilo que é instituído no art. 214, § 1, inciso I, da Constituição de Minas Gerais.

Cumpre ressaltar também que ainda que a DN no 214/2017 versasse efetivamente sobre tema constante na Constituição do Estado ela estaria eivada de vícios. Isso porque ela instaura a obrigação de elaboração e execução do PEA nos processos de Licenciamento Ambiental, sob a forma de Deliberação Normativa.

Por conseguinte, O PEA se volveu um instrumento de controle do andamento dos processos de licenciamento em que se encontra apensado, posto que sua aprovação vem a ser obrigatória para emissão da licença ambiental. Convém lembrar que o Programa de Educação Ambiental deve ser abalizado como um instrumento de gestão e não se converte em um dos documentos do sistema de licenciamento de maior relevância.

Novamente é preciso remontar ao inciso II do art. 5ํํ da CF, o qual diz que "ninguém será obrigado a fazer ou deixar de fazer alguma coisa senão em virtude de lei". Dessa forma, para que uma eventual obrigação fosse criada, ela deveria ser instituída sob a forma de uma Lei, e não de uma Deliberação Normativa, como no caso em tela.

Outro vício presente nas pretensões da DN no 214/2017 é o de que nenhuma das normas hierarquicamente superiores à deliberação em comento traz à baila a obrigação de que o PEA se estruture destinado ao público externo da empresa, tal qual disposto no art. $8^{\circ}, \S 1^{\circ}$, inciso I, da citada DN. Conforme mencionado alhures, a Lei Federal no 9.795/1999 é cristalina ao instituir a promoção da Educação Ambiental apenas para a capacitação dos trabalhadores, sendo silente quanto à necessidade e/ou possibilidade de instituir essa obrigação ao público externo. Lado outro, a Constituição do Estado de Minas Gerais e a Lei no 15.441/2005 não aventam a possibilidade de haver Programa de Educação Ambiental em empresas, muito menos que este seja direcionado ao publico externo.

Assim sendo, resta claro constatar que a Deliberação Normativa $\mathrm{n}^{\circ}$ 214/2017 é, além de inovadora, contrária ao disposto nas normas hierarquicamente superiores, ainda que supostamente mais benéfica ao meio ambiente.

A esse respeito, a jurisprudência do STF (julgamento do Recurso Extraordinário no $586.224 / \mathrm{SP}$ ), afastou a tese de que a norma mais favorável ao meio ambiente deve sempre prevalecer (in dubio pro natura), reconhecendo-se a possibilidade de o regulador distribuir os recursos escassos com vistas à satisfação de outros interesses legítimos, mesmo que não promova os interesses ambientais no máximo patamar possível. Essa tese 
também foi aplicada no conteúdo do importante acórdão das Ações Diretas de Inconstitucionalidade - ADIs no 4.901, 4.902 e 4.903.

Sendo assim, ainda que possivelmente as obrigações instituídas pela DN no 214/2017 sejam mais benéficas ao meio ambiente, esse argumento não é condição sine qua non para que ela seja irrestritamente aplicada. Aliado a isso, ressalta-se o fato de que se trata de uma obrigação que não foi instituída por uma Lei, conforme discorrido anteriormente.

Dessa forma, mesmo que seja ignorado o fato de que a obrigação tenha sido instituída de forma incorreta, ela não encontra previsão e amparo legal em normas hierarquicamente superiores.

É importante abordar a questão da competência concorrente da União e dos Estados para legislarem acerca do assunto aqui tratado. Segundo o art. 24 da $\mathrm{CF} / 88$, inciso VI, compete à União e aos Estados legislar concorrentemente sobre, dentre outros temas, conservação da natureza, proteção do meio ambiente e controle da poluição. Esse tipo de competência é exercido sobre a mesma matéria por mais de uma autoridade ou órgão e, no âmbito da competência concorrente entre as leis, deve-se observar o princípio da hierarquia das normas, em que a legislação federal tem primazia sobre a estadual e municipal (não é sempre primazia, mas ambas devem se ater à sua competência dentro das regras do artigo 24 da CF/88).

Assim sendo, se existe competência concorrente entre União e Estado quanto à conservação da natureza, proteção do meio ambiente e controle da poluição, e nesse tipo de competência a legislação federal tem primazia sobre a legislação estadual, não há que se falar - no caso das normas acerca de Educação Ambiental aqui tratadas - na não predominância daquilo disposto na Lei Federal de Educação Ambiental.

Dessa forma, resta cristalino que deve prevalecer o disposto na Lei Federal no que tange à necessidade de as empresas promoverem a Educação Ambiental apenas para os seus trabalhadores, sem precisar incluir esse tipo de ação para as comunidades vizinhas.

Resta, portanto, argumentar que pode ter havido franco desrespeito ao princípio da legalidade na DN $n^{\circ} 214 / 2017$, visto que a obrigação de elaboração e execução do PEA nos processos de Licenciamento Ambiental não está prevista anteriormente em nenhuma Lei. Além disso, constata-se que a DN em comento, na condição de "demais atos normativos", não obedece a sua função normativa, qual seja, explicitar ou complementar as leis, já que cria uma obrigação completamente inédita em relação às leis preexistentes. 


\section{Conclusões}

Considerou-se que a legislação referente à Educação Ambiental em Minas Gerais, principalmente na instituição da Deliberação Normativa COPAM no 214/2017, se mostra mais restritiva ou burocrática do que aquelas dos demais estados. Essa restrição ou burocracia se dá pelo fato da evolução da legislação, que vai além daquilo que é legislado nos demais estados, representado pela regulamentação do decreto pela DN.

Cabe destacar a Instrução de Serviço do Sistema Estadual de Meio Ambiente e Recursos Hídricos - SISEMA no 04/2018, que apresenta um detalhamento nos procedimentos de análise dos PEAs em relação à DN COPAM no 214/2017. Esse detalhamento da análise demonstra ainda mais esse modelo restritivo.

O compartilhamento da reponsabilidade de disseminar a Educação Ambiental no território brasileiro com a iniciativa privada é visível em todas as normas estaduais. A diferença consiste, porém, na obrigatoriedade estabelecida na Deliberação Normativa mineira, que traz o protagonismo do tema para o empresário e foge, inclusive, daquilo que é disposto no Decreto Estadual no 44.264/2006.

Outro fator determinante na eficácia da Educação Ambiental é a sua área de abrangência. $\mathrm{Na}$ presente análise, não foram coletados dados da eficácia do plano executado em cada Estado, porém, em uma inferência preliminar, entende-se que executar um plano que engloba toda a sociedade pode ser mais efetivo do que determinar microrregiões de acordo com 0 impacto ambiental de cada empresa.

A presente análise não exime - e nem visa fazê-lo - o empreendedor da corresponsabilidade em disseminar a Educação Ambiental, tema primordial na luta pela preservação do meio ambiente. É ponderado apenas o quão protagonista ele deve ser dentro de uma sociedade formada por diversas entidades que fazem usufruto dos recursos naturais e das atividades humanas, bem como os conflitos existentes entre a norma do Estado de Minas Gerais e o disposto em lei federal.

O Decreto Estadual ํo 44.264/2006, que institui a Comissão Interinstitucional de Educação Ambiental do Estado de Minas Gerais, considera que é dever do Estado a promoção da Educação Ambiental. Ao observar o cenário no qual as ações de Educação Ambiental carecem da atuação do Poder Público, muito se discute sobre essa responsabilidade no âmbito municipal ou regional, manifestando-se por meio da implantação de programas fundamentais à execução de uma Política de Educação Ambiental, na qual se consideraria a participação dos diferentes segmentos do Poder Público e também da Sociedade Civil, transformando a Educação Ambiental em algo mais proeminente do proposto na Deliberação.

Por fim, importante mencionar que a maior burocracia ou restrição identificada na legislação do Estado de Minas Gerais, quando comparada aos 
demais Estados da Federação, pode contribuir negativamente para a atração de investimentos e para o ambiente de negócios mineiro, influenciando as indústrias a se instalarem em Unidades Federativas que seguem o disposto na legislação federal.

\section{Referências}

BRASIL. Constituição (1988). Constituição da República Federativa do Brasil. [Brasília]: Senado Federal: Centro Gráfico, 1988.

BRASIL. Lei no 4.281, de 25 de junho de 2002. Regulamenta a Lei $n^{\circ} 9.795$, de 27 de abril de 1999, que institui a Política Nacional de Educação Ambiental, e dá outras providências. Planalto. Disponível em: $<$ http://www.planalto.gov.br/ccivil 03/decreto/2002/D4281.htm\#: :text=Regulam enta\%20a\%20Lei\%20no,que\%20lhe\%20confere\%200\%20art.>. Acesso em: 26 ago. 2020.

BRASIL. Lei $\mathbf{n}^{\circ}$ 9.795, de 27 de abril de 1999. Dispõe sobre a Educação Ambiental, institui a Política Nacional de Educação Ambiental e dá outras providências. Planalto. Disponível em: <http://www.planalto.gov.br/ccivil 03/leis/19795.htm>. Acesso em: 26 ago. 2020. BRASIL. Supremo Tribunal Federal. Ação Direta de Inconstitucionalidade no 4.901. 2018. P. 2, $3, \quad 7 \quad$ e 8. Disponível em: $<$ http://portal.stf.jus.br/processos/downloadPeca.asp?id=15340792363\&ext=.pd f>. Acesso em: 11 ago. 2020.

BRASIL. Supremo Tribunal Federal. Ação Direta de Inconstitucionalidade no 4901. $2018 . \quad$ P. $51 . \quad$ Disponível em: $<$ http://portal.stf.jus.br/processos/downloadPeca.asp?id=15340792363\&ext=.pd f>. Acesso em: 11 ago. 2020.

CEARÁ. Lei no 14.892, de 31 de março de 2011. Dispões sobre a Educação Ambiental, institui a Política Estadual de Educação Ambiental e dá outras providências. Diário Oficial do Estado. Fortaleza, CE, 4 abr. 2011.

CEARÁ. Secretaria de Meio Ambiente do Estado do Ceará. Programa de Educação Ambiental do Ceará. [FORTALEZA]: CIEA, Secretaria de Meio Ambiente do Estado do Ceará, 2017, 116 p.

DELORS, J. Educação um Tesouro a Descobrir - Relatório para a Unesco da Comissão Internacional sobre a Educação Para o Século XXI. Brasília, DF: Unesco, 1998.

DISTRITO FEDERAL. Câmara Legislativa do Distrito Federal. Decreto no 31.129, de 4 de março de 2009. Regulamenta a Lei no 3.833, de 27 de março de 2006, que dispõe sobre a Educação Ambiental, institui a Política de Educação Ambiental do Distrito Federal, cria o Programa de Educação Ambiental do Distrito Federal, complementa a Lei Federal no 9.795/1999 no âmbito do Distrito Federal e dá outras providências. Diário do Executivo, Brasília, DF, 4 dez. de 2009. 
DISTRITO FEDERAL. Câmara Legislativa do Distrito Federal. Lei no 3.833, de 4 de dezembro de 2006. Dispõe sobre a Educação Ambiental, institui a Política de Educação Ambiental do Distrito Federal, cria o Programa de Educação Ambiental do Distrito Federal, complementa a Lei Federal no 9.795/1999 no âmbito do Distrito Federal e dá outras providências. Diário do Executivo, Brasília, DF, 30 mar. 2006.

GOIÁS. Decreto $\mathbf{n}^{\circ} \mathbf{7 . 8 2 1}$, de 5 de março de 2013. Institui o Programa Estadual de Educação Ambiental e dá outras providências. Assembleia Legislativa do Estado de Goiás. Disponível em: https://legisla.casacivil.go.gov.br/pesquisa legislacao/66130/decreto7821\#: : :text=Decreto\%20Numerado\%20n\%C2\%B0\%207.821\%20\%2F\%20201 3\&text=Institui\%200\%20Programa\%20Estadual\%20de\%20Educa\%C3\%A7\%C 3\%A30\%20Ambiental\%20e\%20d\%C3\%A1\%20outras\%20provid\%C3\%AAncias . Acesso em: 26 ago. 2020.

GOIÁS. Lei no 16.586, de 16 de junho de 2009. Dispõe sobre a Educação Ambiental, institui a Política Estadual de Educação Ambiental e dá outras providências. Assembleia Legislativa do Estado de Goiás. Disponível em: https://legisla.casacivil.go.gov.br/pesquisa legislacao/88041/lei-16586. Acesso em: 26 ago. 2020.

JACOBI, P. Educação Ambiental. Cidadania e Sustentabilidade. São Paulo. USP, 2002. p. 10.

MARANHÃO. Decreto $\mathbf{n}^{\circ} \mathbf{2 8 . 5 4 9}$, de 31 de agosto de 2012. Dispõe sobre a regulamentação da Lei $n^{\circ}$ 9.279, de 20 de outubro de 2010, que institui a Política Estadual de Educação Ambiental e o Sistema Estadual de Educação Ambiental do Estado do Maranhão. Secretaria de Transparência e Controle. Disponível em: <http://stc.ma.gov.br/legisla-documento/?id=4700>. Acesso em: 29 ago. 2020.

MARANHÃO. Lei $\mathbf{n}^{\circ} \mathbf{9 . 2 7 9}$, de 20 de outubro de 2010. Institui a Política Estadual de Educação Ambiental e o Sistema Estadual de Educação Ambiental do Maranhão. Secretaria de Transparência e Controle. Disponível em: http://stc.ma.gov.br/legisla-documento/?id=4699. Acesso em: 29 ago. 2020.

MATO GROSSO. Conselho Estadual de Educação de Mato Grosso. Resolução Normativa no 002, de 24 de setembro de 2015. Estabelece normas aplicáveis para a Educação Básica no Sistema Estadual de Ensino e dá outras providências. Diário Oficial, 24 set. 2015.

MATO GROSSO. Lei $\mathbf{n}^{\circ} \mathbf{1 0 . 9 0 3}$, de 7 de junho de 2019. Dispõe sobre a Política Estadual de Educação Ambiental e revoga a Lei no 7.888 , de 9 de janeiro de 2003. Assembleia Legislativa do Estado de Mato Grosso.

MINAS GERAIS. Constituição do Estado de Minas Gerais, 25 edição, janeiro de 2020. Atualizada e acompanhada dos textos das Emendas à Constituição no 1 a 103. Assembleia Legislativa de Minas Gerais. Disponível em: $\quad<$ https://www.almg.gov.br/consulte/legislacao/index.html?aba=js tabCons tituicao Estadual\&tipoPesquisa $=$ constituicaoEstadual\&ceArtigo $=214>$. Acesso em:26 ago. 2020

Revbea, São Paulo, V. 16, № 6: 378-396, 2021. 
MINAS GERAIS. Decreto $n^{\circ}$ 44.264, de 24 de março de 2003. Assembleia Legislativa de Minas Gerais. Disponível em: $<$ https://www.almg.gov.br/consulte/legislacao/completa/completa.html?tipo=DE C\&num $=44264 \&$ comp $=\& a n o=2006 \& a b a=$ is textoAtualizado\#texto $>$. Acesso em: 26 ago. 2020.

MINAS GERAIS. Deliberação Normativa n 214, de 26 de abril de 2017. Estabelece as diretrizes para a elaboração e a execução dos Programas de Educação Ambiental no âmbito dos processos de licenciamento ambiental no Estado de Minas Gerais. Sistema Integrado de Informações Ambientais. Disponível em: $<$ http://www.siam.mg.gov.br/sla/download.pdf?idNorma=44198>. Acesso em: 26 ago. 2020.

MINAS GERAIS. Deliberação Normativa n 238, de 26 de agosto de 2020. Altera a Deliberação Normativa Copam oㅡ 214, de 26 de abril de 2017, que estabelece as diretrizes para a elaboração e a execução dos Programas de Educação Ambiental no âmbito dos processos de licenciamento ambiental no Estado de Minas Gerais. Sistema Integrado de Informações Ambientais. Disponível em: <http://www.siam.mg.gov.br/sla/action/consultaPublicacoes $>$. Acesso em: 26 ago. 2020.

MINAS GERAIS. Lei $\mathbf{n}^{\circ} \mathbf{1 5 . 4 4 1}$, de 11 de janeiro de 2005. Regulamenta o inciso I do $\S 1^{\circ}$ do art. 214 da Constituição do Estado. Assembleia Legislativa de Minas Gerais. Disponível em: $<$ https://www.almg.gov.br/consulte/legislacao/completa/completa.html?tipo=LEI \&num $=15441 \& \mathrm{comp}=\& a n o=2005 \& a b a=j s$ textoAtualizado $>$. Acesso em: 26 ago. 2020.

MINAS GERAIS. Sistema Estadual de Meio Ambiente e Recursos Hídricos. Instrução de Serviço SISEMA no 04/2018. Dispõe sobre os procedimentos e as diretrizes a serem cumpridas para a elaboração, análise e acompanhamento dos Programas de Educação Ambiental exigíveis no âmbito dos processos administrativos de licenciamento ambiental no Estado de Minas Gerais, em cumprimento à Deliberação Normativa COPAM no 214, de 26 de abril de 2017.2 Disponível em: <http://www.meioambiente.mg.gov.br/images/stories/2018/PADRONIZA\%C3\% 87\%C3\%830 PROCEDIMENTOS/Instru\%C3\%A7\%C3\%A3o de Servi\%C3\% A70 Sisema 04.2018 - Educa\%C3\%A7\%C3\%A30 Ambiental.pdf>. Acesso em: 15 set. 2020.

ORGANIZAÇÃO DAS NAÇÕES UNIDAS. Declaração da Conferência das Nações Unidas sobre o Meio Ambiente Humano. Tradução livre. Estocolmo, jun. 1972. Disponível em: <https://cetesb.sp.gov.br/proclima/conferenciasinternacionais-sobre-o-meio-ambiente/estocolmo/>. Acesso em: 26 jan. 2021. 
PARAÍBA. Palácio do Governador do Estado da Paraíba. Decreto no 36.156, de 9 de setembro de 2015. Regulamenta a Lei ํㅜ 3.833, de 27 de março de 2006, que dispõe sobre a Educação Ambiental, institui a Política de Educação Ambiental do Distrito Federal, cria o Programa de Educação Ambiental do Distrito Federal, complementa a Lei federal no 9.795/1999 no âmbito do Distrito Federal e dá outras providências. Diário do Executivo, João Pessoa, PB, 9 set. de 2015.

PARAÍBA. Poder Legislativo da Paraíba. Lei no 7.718, de 6 de janeiro de 2005. Dispõe sobre a Educação Ambiental, institui a Política de Educação Ambiental do Distrito Federal, cria o Programa de Educação Ambiental e complementa a Lei federal no 9.795/1999 no âmbito do Estado da Paraíba. Diário do Executivo, João Pessoas, PB, 6 jan. 2005.

RELATÓRIO BRUNDTLAND. Nosso Futuro Comum. Disponível em: $<$ http://pt.scribd.com/doc/12906958/Relatorio-Brundtland-Nosso-FuturoComum-Em-Portugues >. Acesso em: jan. 2021.

SÁNCHEZ, L.H. Avaliação de Impacto Ambiental: Conceitos e Métodos. 2 ed. São Paulo: Oficina de Textos, 2013.

SANTA CATARINA. Lei $\mathbf{n}^{\circ} \mathbf{1 3 . 5 5 8}$, de 17 de novembro de 2005. Dispõe sobre a Política Estadual de Educação Ambiental - PEEA - e adota outras providências. Assembleia Legislativa de Santa Catarina. Disponível em: $<$ https://www.fundai.sc.gov.br/files/legislacoes/legislacao 58.pdf>. Acesso em: 29 ago. 2020.

SANTA CATARINA. Decreto $\mathbf{n}^{\circ}$ 3.726, de 14 de dezembro de 2010. Regulamenta o Programa Estadual de Educação Ambiental de Santa Catarina - ProEEA/SC. Assembleia Legislativa de Santa Catarina. Disponível em: $<$ http://server03.pge.sc.gov.br/LegislacaoEstadual/2010/003726-005-0-2010003.htm>. Acesso em: 29 ago. 2020.

SÃO PAULO. Decreto $n^{\circ}$ 63.456, de 5 de junho de 2018. Regulamenta a Política Estadual de Educação Ambiental, instituída pela Lei oㅜ 12.780, de 30 de novembro de 2007, institui a Comissão Interinstitucional de Educação Ambiental e dá providências correlatas. Assembleia Legislativa do Estado de São Paulo. Disponível em: $<$ https://www.al.sp.gov.br/repositorio/legislacao/decreto/2018/decreto-6345605.06.2018.html>. Acesso em: 29 ago. 2020.

SÃO PAULO. Lei $\mathbf{n}^{\circ} \mathbf{1 2 . 7 8 0}$, de 30 de novembro de 2007. Institui a Política Estadual de Educação Ambiental. Assembleia Legislativa do Estado de São Paulo. Disponível em: https://www.al.sp.gov.br/repositorio/ legislacao/lei/2007/lei-12780-30.11.2007.html. Acesso em: 29 ago. 2020.

SEARA FILHO, G. Apontamentos de introdução à Educação Ambiental. Revista Ambiental, a. 1, v. 1, p. 40-44, 1987.

UNESCO-UNEP International strategy for action in the field of environmental education and training for the 1990s. Paris: UNESCO e Nairobi. 1987. 